\title{
BMJ Open Leadership development in complex health systems: a qualitative study
}

\author{
Leslie A Curry (D , ${ }^{1,2}$ Adeola A Ayedun, ${ }^{1,2}$ Emily J Cherlin, ${ }^{1,2}$ Nikole H Allen, ${ }^{1,3}$ \\ Erika L Linnander ${ }^{1,2}$
}

To cite: Curry LA, Ayedun AA, Cherlin EJ, et al. Leadership development in complex health systems: a qualitative study. BMJ Open 2020;10:e035797. doi:10.1136/ bmjopen-2019-035797

\section{- Prepublication history and} additional material for this paper are available online. To view these files, please visit the journal online (http://dx.doi. org/10.1136/bmjopen-2019035797).

Received 19 November 2019 Revised 28 February 2020 Accepted 12 March 2020

Check for updates

(C) Author(s) (or their employer(s)) 2020. Re-use permitted under CC BY-NC. No commercial re-use. See rights and permissions. Published by BMJ.

${ }^{1}$ Health Policy and Management, Yale School of Public Health,

New Haven, Connecticut, USA

${ }^{2}$ Global Health Leadership Initiative, Yale School of Public Health, New Haven, Connecticut, USA

${ }^{3}$ Yale Institute for Global Health, Yale School of Public Health, New Haven, Connecticut, USA

Correspondence to

Leslie A Curry;

leslie.curry@yale.edu

\section{ABSTRACT}

Objective Leadership is associated with organisational performance in healthcare, including quality, safety and clinical outcomes for patients. Leadership development programmes have proliferated in recent years.

Nevertheless, very few have examined participant experiences in depth in order to understand which programmatic aspects they regard as most valuable relative to leadership in increasingly complex systems, or whether and how learnings may sustain over time. Accordingly, we explored experiences of participants in an interdisciplinary leadership development programme using qualitative methods over an extended look-back period. Setting Health and social care sectors in the UK. Participants Key informants from three cohorts of individuals working in leadership roles in health and social care in the UK: $2013 / 2014,2015 / 2016$ and $2017 / 2018$. We contacted 32 participants, and 26 completed interviews (81\% response rate).

Primary and secondary outcomes We explored (1) whether and how specific skills and competencies developed during the programme were applied and/or sustained over time, and (2) whether and how the impact of the programme changed as alumni progressed through their career.

Results Three major recurrent themes emerged from participants' experiences: (1) specific features of the programme meaningfully impact professional development at multiple levels; (2) the coupling of a professional network and practical tools allowed participants to address system-wide problems in new ways and (3) participants describe a level of learning that sustained and amplified over time with increased complexity in their work. Conclusion This work highlights specific design characteristics of leadership development programmes that may help promote relevance and impact. Programme learnings can be translated into practice in substantive ways, with potential for the benefits of successful leadership development efforts to amplify, not fade, over time.

\section{INTRODUCTION}

Leadership is associated with multiple aspects of organisational performance in healthcare, ${ }^{1}$ including quality and safety, ${ }^{23}$ as well as clinical outcomes for patients. ${ }^{4-9}$ Leadership development programmes have proliferated in recent years; however, few have integrated current evidence regarding the nature
Strengths and limitations of this study

- Although leadership development programmes are ubiquitous, very few have examined participant experiences longitudinally to determine programmatic aspects most useful for leadership in complex systems, and whether or how learnings are retained.

- Very few prior studies of leadership programmes have used qualitative methods, which are optimal for exploring this topic; this study relies on in-depth interviews, providing rich descriptions of participant experiences

- Major limitations include potential for social desirability bias and lack of quantitative impact measures.

of leadership in complex systems, which requires new competencies such as creativity in strategic problem solving and managing organisational dynamics. ${ }^{10-12}$ Despite increasing understanding of the importance of interdisciplinary leadership teams, ${ }^{11}{ }^{13}$ most leadership development programmes for healthcare executives focus on individual leadership skills (vs systems capacity), include single disciplines or professions (rather than interdisciplinary or interprofessional teams), focus on technical (as opposed to adaptive) ${ }^{14}$ skills and are designed for early-to-mid career clinicians who have limited leadership roles. ${ }^{15}$ Furthermore, problem-focused leadership development ${ }^{16-19}$ and using diverse teams is associated with more effective learning ${ }^{20}$ and improved outcomes, such as quality indicators for disease management. ${ }^{21}{ }^{22}$ Yet relatively few leadership programmes integrate field-based leadership projects as a central curricular component. ${ }^{15}$

Recent surveys indicate that there is wide variation in approaches to healthcare leadership development, and evidence regarding best practices is still emerging. ${ }^{23}$ A 2014 systematic review of 250 health leadership education programmes concluded that, due to high variability in programs and limited evaluation data, it was not possible to identify best practices in terms of learning context, 
content, activities and delivery mechanisms. ${ }^{24}$ In particular, there is limited knowledge regarding the relevance and impact of specific structural and curricular design features of leadership programmes. ${ }^{19}$ Evidence is largely limited to quantitative pre-post self-assessment of individual-level competencies and satisfaction immediately on completion; more nuanced participant views regarding programmatic elements most valuable for leadership in complex systems, or longer term influences are not well described..$^{1524}$

Accordingly, we conducted an in-depth exploration of participant experience in an interdisciplinary leadership development programme using qualitative methods over an extended look back period. We sought to identify specific structural and curricular design characteristics of leadership development programmes that may promote learnings that sustain over time. Our findings may be helpful to clinicians and policy makers seeking to create robust educational programmes to improve both individual-level and system-level leadership capacity in increasingly complex health and care systems.

\section{METHODS}

\section{Study setting}

The study was conducted in the context of the Yale Strategic System Leadership Programme for Sustainability and Transformation Partnership (STP) Footprints, launched in 2007 and initially underwritten by South Essex Partnership NHS Foundation Trust with participants funded by their organisation or system; subsequent funders include Health Education England and the National Leadership Academy. Participants included senior system leaders in the National Health Service (NHS; including providers, commissioners and executives) and, beginning in 2017, teams of three from 10 STPs including a senior clinical lead, managerial lead and another sector (eg, local authority, wider public sector and third sector). Delegates participated in a 6-day, residential-style module in England, conducted mentored field projects over a 9-month period and participated in a second 6-day residential-style module at Yale University in the USA (figure 1). A description of programme objectives, structural and curricular features is provided in Box 1. Because this programme explicitly addressed leadership development in complex health systems, it serves as a useful setting in which to explore the relevance and value of specific structural and curricular design features.

\section{Study design}

We conducted a qualitative study using in-depth interviews with key informants ${ }^{25}$ from three cohorts: 2013/2014, 2015/2016 and 2017/2018 in order to elicit experiences from delegates who have varying lengths of time from programme completion. We used a random sampling approach, with systematic attention to ensuring diversity in terms of gender, role and geography. ${ }^{25}$ First, we separately randomised the lists of alumni from each cohort. Next, we worked in sequence through the randomised list of each cohort, beginning with the first and sequentially choosing individuals to ensure that the selected group was diverse across above-noted criteria based on data at the time of course enrollment.

We sought to recruit approximately 30 alumni by email (10 from each of the three cohorts) for interviews, consistent with a priori sample size recommendations by qualitative experts. ${ }^{25}{ }^{26}$ In total, 32 delegates were contacted, and 26 completed interviews ( $81 \%$ response rate). Two individuals who declined cited medical emergencies and

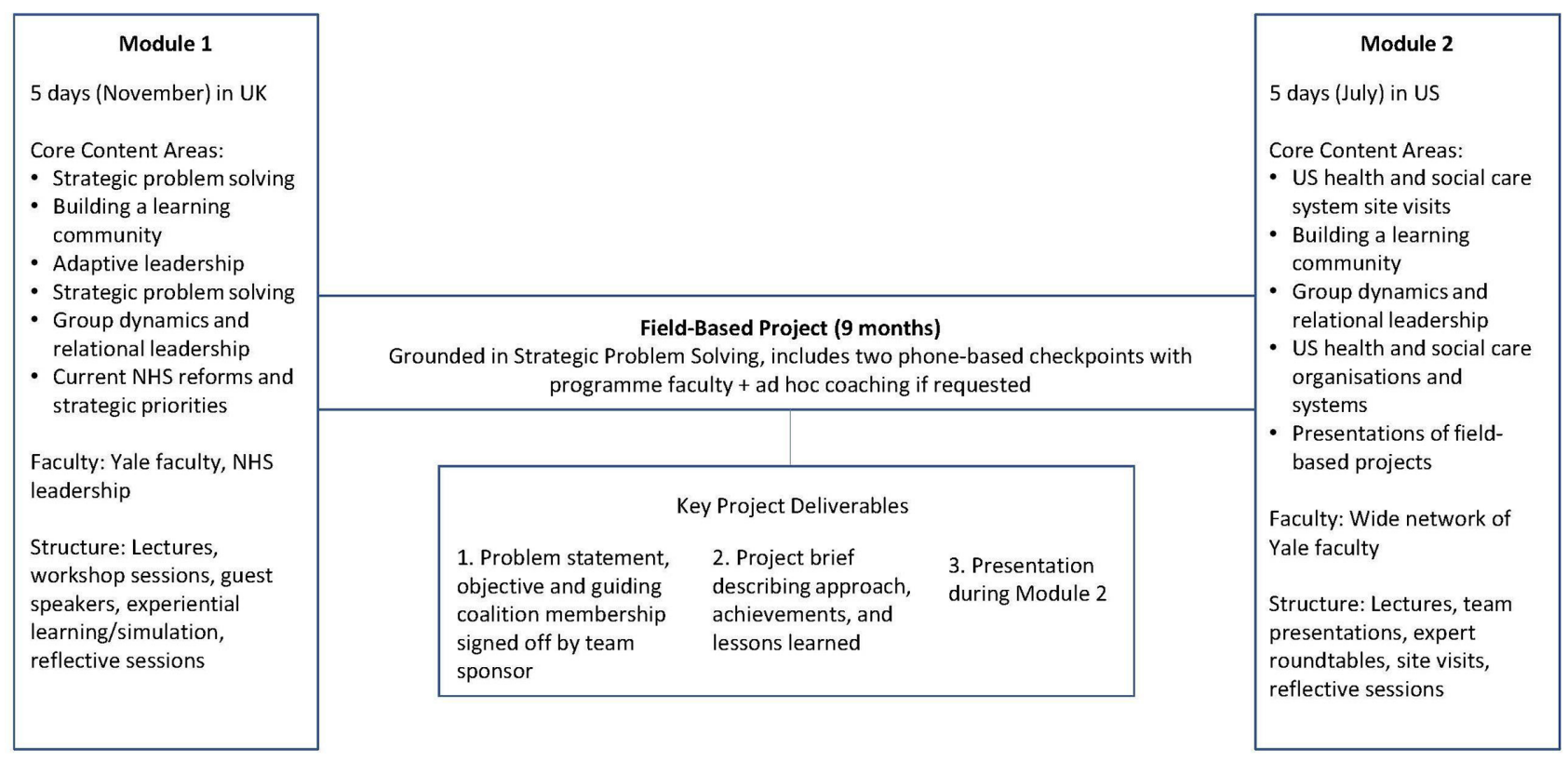

Figure 1 Programme frame. 
Box 1 Description of programme objectives, structural and curricular features

\section{Objectives:}

- Strengthen leadership capability among teams to solve complex challenges in health and social care.

- Foster effective relationship management across diverse groups and system-wide boundaries.

- Provide the analytical and behavioural science tools needed to deliver robust strategic change within their systems.

- Explore the international context of health and social care through a comparative lens.

Partner roles:

- UK partner manages the participant application and selection process, provides psychometric testing and fitness services, identifies and arranges speakers from the UK health and social care system, manages programme logistics in the UK and travel to the USA and provides periodic check-ins to participants as they complete the field project.

- US partner manages and delivers curricular content, identifies and arranges US site visits and speakers, manages programme logistics in the USA, provides feedback to participants at field project milestones and certifies completion.

Overall design:

- Two residential 6-day retreat modules (first in the UK, second in the USA).

- A 9-month field project to address a complex adaptive challenge in health and social care.

- Certificate of completion issued by Yale School of Public Health.

Participant composition:

- Individuals (cohorts 2013/2014 and 2015/2016; teams of three (beginning in 2017/2018).

- Diverse individuals (eg, clinical and non-clinical backgrounds, gender and other protected characteristics).

- Cross-organisational and sectoral representation (health, social care, local government, most recent cohort).

- Sufficient level of seniority within their organisation to effect change.

- Endorsement from senior leader for time in the programme and support for the field project.

\section{Curricular content}

Didactics and table top exercises

- Working across boundaries ${ }^{4748}$ and in hierarchy. ${ }^{49} 50$

- Leadership and followership. ${ }^{51}$

- Representational group theory. ${ }^{52-54}$

- Psychological safety. ${ }^{3}$

Levels of analysis ${ }^{55} 56$

\section{Keynote lectures}

- UK speakers on national strategic priorities and current reforms.

- Breaking science from the Yale team's research on leadership, management, culture and organisational performance.

- Site visits and roundtables with practitioners/experts on US health and social care.

Strategic problem-solving methodology ${ }^{157}$

Define the problem and objective.

- Identify and prioritise root causes.

- Generate and pursue strategic solutions.

- Measure progress and impact.

Individual psychometric evaluations (optional)

- 15FQ+; ${ }^{58}$ Watson-Glaser Critical Thinking Appraisal (UK); ${ }^{59}$ MyersBriggs Type Indicator (MBTI); ${ }^{60}$ StressScan Indicator. ${ }^{61}$

Continued

\section{Box 1 Continued}

- Administered via online survey, followed by personal feedback sessions with a UK-based organisational development consultant during the first programme module.

Field project:

- Participants are supported to the following:

- Identify a problem of strategic importance to the organisation or system.

- Convene a guiding coalition ${ }^{1362}$ of diverse stakeholders that can understand and address the problem.

- Facilitate the guiding coalition through the strategic problemsolving process, integrating new perspectives on organisational dynamics.

- Participants produce deliverables for faculty feedback:

- Problem statement, objective, coalition members and sponsor sign-off.

- Three-page written summary of project progress and leadership reflections.

- Oral presentation to faculty and peers during module 2.

Supports for participant well-being:

- Optional daily group exercise class and individual fitness/nutrition consultations.

Development of a learning community:

- Daily check-ins to allow for real-time feedback and course corrections.

- Opening and closing facilitated reflection sessions to promote learning intentions, build relationships, and synthesise experiences.

- Creation of WhatsApp group created in week 1 (beginning cohort 2017/2018; Linkedln in prior cohorts) to support continued connection among participants.

professional role as reasons for not participating. Three individuals agreed but missed their appointments. One individual did not respond. Of the 26 participants who agreed to be interviewed, 10 were from the $2017 / 2018$ cohort (from a total of 31), seven from the 2015/2016 cohort (from a total of 16) and nine from the 2013/2014 cohort (from a total of 16). We reached thematic saturation (ie, no new concepts emerging with subsequent interviews) with this sample. ${ }^{27}$

All members of the research team had some experience with the programme, consistent with the principle of 'the evaluator as instrument ${ }^{28}$ to generate novel insights and situate the findings in what is known. We intentionally assigned team roles to maximise the generativity of data collection efforts and to capitalise on experts' skills in the analysis phase (where all data were anonymous). Interviews were conducted by two research associates (AA and NHA) with experience in developing rapport while preserving social and intellectual distance. ${ }^{29}{ }^{30}$ We anticipated there would be few, if any, power dynamics in the conversation given the interviewers were research assistants who have no power to impact participant's careers or professional development. Because participants have nothing to gain from reporting positive experiences, or to lose from reporting negative experiences, we anticipated that fear of reprisal or social desirability bias would be minimal. In addition, we believed alumni desire to 
provide constructive criticism was likely to counterbalance social desirability bias towards positive reflections; nevertheless, we note social desirability as a possible limitation of the study. Senior team members (LC, EL and EC) participated in data analysis and interpretation, to facilitate 'shared understanding' and produce meaning. ${ }^{30}$

\section{Data collection}

All interviews were conducted via phone using a standard discussion guide (see online supplementary table 1) after informed consent (including stating the goals of the study) was obtained. The guide consisted of 'grand tour' questions ${ }^{31}$ to elicit study participants' perspectives. Probes were used to generate 'thick descriptions' of their experiences, as well as to elicit both positive and negative views. ${ }^{32}{ }^{33}$ Participants were encouraged to share negative views through probes such as What did not work so well? What was not as worthwhile? What was not as relevant? Interviews were digitally recorded, professionally transcribed, and reviewed to ensure accuracy.

\section{Data analysis}

A four-person multidisciplinary team used the constant comparative method of data analysis. ${ }^{34-36}$ The full team independently coded four transcripts, developing codes to classify data inductively, drafting an integrated code structure. We then broke into teams of two, each team coding half of the remaining transcripts. We resolved differences in coding by consensus. The final code structure was reapplied to all transcripts. We identified prominent and unifying themes across all three cohorts; in addition, we systematically examined differences between the three cohorts. We used established techniques to ensure that data collection and analysis were systematic and verifiable. ${ }^{3637}$ We used Atlas.ti V.8.

\section{Patient and public involvement}

There were no patients involved in this study.

\section{RESULTS}

Characteristics of the study participants are reported in table 1 .

Interviews were $20-50 \mathrm{~min}$ in duration (mean $35 \mathrm{~min}$ ). Three major recurrent themes emerged from participants' experiences (table 2): (1) specific features of the programme meaningfully impact professional development at multiple levels; (2) the coupling of a professional network and practical tools allowed participants to address system-wide problems in new ways and (3) participants describe a level of learning that sustains and amplifies over time with increased complexity in their work. These themes were recurrent across all cohorts; there were no substantive differences in views across the cohorts.

We provide illustrative quotations below; please see additional quotations in online supplementary table 2. Some participant feedback included critical or negative comments related to the following aspects of the

\begin{tabular}{lll}
\hline \multicolumn{3}{l}{ Table 1 Characteristics of study participants } \\
\hline Characteristic & $\begin{array}{l}\text { Participants } \\
\mathrm{n}=26\end{array}$ & $\begin{array}{l}\text { Total sample } \\
\mathrm{n}=63\end{array}$ \\
$\begin{array}{l}\text { Gender } \\
\text { Male }\end{array}$ & $14(54 \%)$ & $27(43 \%)$ \\
\hline Female & $12(46 \%)$ & $36(57 \%)$ \\
Cohort & \\
\hline Year 2017-2018 & $10(38 \%)$ & $31(50 \%)$ \\
\hline Year 2015-2016 & $7(27 \%)$ & $16(25 \%)$ \\
\hline Year 2013-2014 & $9(35 \%)$ & $16(25 \%)$ \\
Region & & \\
\hline North & $3(11 \%)$ & $8(13 \%)$ \\
\hline Midlands and East & $16(62 \%)$ & $38(60 \%)$ \\
\hline London & $1(4 \%)$ & $3(5 \%)$ \\
\hline South West & $0(0 \%)$ & $5(8 \%)$ \\
\hline South East & $5(19 \%)$ & $7(11 \%)$ \\
\hline National & $1(4 \%)$ & $2(3 \%)$ \\
\hline Seniority & & \\
\hline Board & $18(69 \%)$ & $38(60 \%)$ \\
\hline Senior Manager & $7(27 \%)$ & $21(34 \%)$ \\
\hline Other National & $1(4 \%)$ & $4(6 \%)$ \\
\hline Clinician & & $16(25 \%)$ \\
\hline Clinician & $9(35 \%)$ & $47(75 \%)$ \\
\hline Non-clinician & $17(65 \%)$ & \\
\hline & & \\
\hline
\end{tabular}

programme: networking opportunities, course content, participant selection and cost. These comments are reported in online supplementary table 3 .

\section{Specific features of the programme meaningfully impact professional development at multiple levels}

Participants described five features of the programme that they experienced as highly relevant and valuable. First, the presentation of newly generated scientific evidence relevant to working in complex systems (such as the Leadership Saves Lives study) was regarded as particularly compelling since it demonstrated that organisational culture could be improved through intervention: " the research they were giving was hot off the press. That was so exciting'. One participant shared how access to the latest scientific evidence on the role of social determinants of health ${ }^{38}$ in improving health outcomes and reducing spending supported her in navigating key relationships with our local authorities...the course gave me that evidence, especially trying to relate as much as possible the health and the social component'.

Second, the field work component of the programme resonated strongly with participants, who reflected on the value of project-based learning, especially teambased approaches. Exemplar projects focused on quality and safety issues included aligning the STP to national 


\begin{tabular}{ll} 
Theme & Subthemes \\
$\begin{array}{l}\text { Specific programme features meaningfully impact } \\
\text { professional development at multiple levels }\end{array}$ & $\begin{array}{l}\text { Cutting edge science; practical field project experience; emphasis on } \\
\text { relational leadership fits with UK context; fostering of a diverse learning } \\
\text { community; direct and multifaceted exposure to the US system }\end{array}$ \\
$\begin{array}{ll}\text { The coupling of a professional network and practical } \\
\text { tools allowed participants to address system-wide } \\
\text { problems in new ways }\end{array}$ & $\begin{array}{l}\text { Robust professional network for both information and inspiration; } \\
\text { strategic problem solving; relational leadership to engage diverse } \\
\text { stakeholders }\end{array}$ \\
$\begin{array}{ll}\text { Participants describe a level of learning that } \\
\text { sustained and amplified over time with increased } \\
\text { complexity in their work }\end{array}$ & $\begin{array}{l}\text { Carrying learnings forward; tools become ingrained; increase in relevancy } \\
\end{array}$ \\
\hline
\end{tabular}

average benchmarks for admission rates, length of stay and mortality for patients with heart failure and reducing the number of avoidable falls in mental health inpatient areas. One participant from NHS implemented a field project with peers from social care and local government, remarking that working as a 'triumvirate of equals' was entirely new. Conducting a field project allowed participants to 'very, very swiftly' apply the theory to practice, which was distinct from other courses and prevented the learnings from 'dissipating'.

Sometimes you attend courses that are very theoretical and, although you know that you can apply them to a practical problem, you don't often do it immediately. Then the learning sort of dissipates by the time you then have a project to actually do. Running the projects alongside the course, because you were immersed in this theory of it, you were able to apply that very, very swiftly to the project in hand, which meant it made it a much easier way of putting the theory into practice. (Interview 9 Female, Clinician, Senior Manager)

Furthermore, for some, the combination of these first two components-academic rigour and practical implementation experience-was regarded as both novel and 'brilliant':

That mix of academic and practical really, really works. The U.K. base, the U.S. base, and the teaching work together. Even when we went to the US, we were able to ground it in what's happening in the U.K. The difference was the rigor of the academic foundation of this programme. That's important. But also, for me, that leap to the practical implementation was brilliant. It wasn't one or the other. It did both. (Interview 3 Female, Senior Manager).

Third, participants also reflected that the programme content was especially relevant in the UK context, which some experienced as characterised by competition among diverse stakeholders. They observed that 'barriers between the professionals unfortunately is a real problem in the UK' and 'certain sections of systems are quite closed'. Through team-based collaborative field projects, participants strengthened their abilities to address challenges they experience in the UK (and are inherent in most health systems):

During my project, I used the techniques for exploring and resolving conflicts between teams. Subsequently, when I moved hospitals, there was a major conflict between two important elements of my sphere of influence, and I used them again...I don't know whether British people argue more or have more fights than Americans or not, but it's a common thing to require addressing...so I've used that repeatedly. (Interview 1 Male, Board member).

Fourth, cohorts were diverse in terms of professional roles, organisational homes and sectors, gender, seniority. Participants reported that this diversity and substantive attention to building a psychologically safe learning community prepared them to communicate more openly and effectively with groups at different levels of the system and across sectors. Both facilitated and informal interactions with diverse peers 'cemented' relationships and provided energy to persist with a 'really, really difficult job'. This diversity generated a sense of solidarity, as peers 'face very similar challenges in, nationally speaking, the same organization, but on the other hand from quite diverse organizations'.

The programme enables you to talk about system transformation with every stakeholder at every level. It gives you the tools... The fact that we had people from local authorities and the voluntary sector, we got a lot out of that, and I hope that they did too because I think you can start to think in a particular way if you've only ever worked in the NHS. (Interview 12 Female, Board member).

The learning community balanced academic rigour within a learning culture to create a supportive environment. Participants noted the prestige of 'being at Yale gives you a different frame of mind, the minute you go in'. At the same time, participants also highlighted the 'ease of learning' supported by fostering a culture that inspired confidence and motivation. They characterised this learning environment as a (psychologically) 'safe space', allowing them to be vulnerable with other professionals 
about their challenges ('I was heard and listened to'). One participant reflected bringing people from different levels within the system together in a supportive space allowed for free exchange of ideas:

I work at a national level, and it was really useful to speak to a whole series of people who work in different roles at the local level to understand their perspective, to be able to test things with them, and to understand what the situation was on the ground... It's often in a professional environment when you talk to local groups. They want to put forward the best view or to push their particular agenda, whereas this gave us a very relaxed environment in which you could have those conversations where people felt that they could be more open and there wasn't a challenging relationship. (Interview 20 Male, National Level).

Fifth, most, but not all, participants found the direct and multifaceted exposure to the US healthcare system enabled them to view their own system from a new perspective, recognising that challenges they experience are not unique. For some, innovations in the USA catalysed new ideas, and for others, learning about the US system served as a reminder that the UK system has many advantages.

The other really, really interesting bit for me was understanding some of the challenges and advances and differences between our healthcare system, and, particularly, the U.S. healthcare system, where there are bits that are fantastic, and there are bits that are not so fantastic. It was a lot of that cross learning and understanding of where the journeys are. (Interview 21 Male, Clinician, Board Member).

\section{Coupling of a professional network and practical tools allowed participants to address system-wide problems in new ways}

First, most, but not all, participants asserted the programme cultivated a robust social network that has provided them with 'common language and common understanding', allowing them to increase their impact as they address problems within their systems (eg, 'what is the problem?' and 'let people have their groups'). Participants from the same STP or Integrated Care System collaborated beyond the confines of the programme, although one observed 'there was no way to facilitate people...to see whether there would be joint possibilities to work on strategies'. Networks began with intentional facilitation within the programme, have sustained past completion and expanded across cohorts (see online supplementary table 2 for quotations describing network formation). For example, a vibrant WhatsApp group has become a place for sharing ideas and continuing the learning beyond the programme:

Since working on the programme, we have actually worked together on a number of other projects. It widened my horizons within my own STP, meeting people I didn't even know...We're very much in touch as a team. We've got a WhatsApp group and people are posting stuff on there all the time... we find that we approach situations from the same angle. We have a common language and a common understanding. Even if we debate and discuss strategies or root cause of an issue we always go back to what we've learned. (Interview 2 Female, Clinician, Senior Manager).

Second, participants described applying specific tools they learnt in the programme to support their work in integrating health and social care across systems (see online supplementary table 2 for additional examples). Practical, concrete methods of strategic problem solving $^{1}$ spurred new ways of thinking. One participant reflected on the value of framing problems more systematically: 'the idea that you should devote a much higher proportion of your time to trying to understand what the problem is before you start trying to dream up solutions was a transforming insight for me'. Participants described working in complex systems with 'difficult landscapes' and developed an appreciation for being prepared to address this complexity: "leadership is about having a whole toolbox and lots and lots of different tools and learning when and how to use them'. The ability to carry out authentic stakeholder engagement as part of systematic, strategic problem solving was characterised as a new competency by many:

What has been very interesting is beginning to apply the problem solving methodology to the problems that we've had... Now having sat down and applied this methodology, I realize that it was never applied at all in the first place, and that's probably one of the reasons that our proposals effectively failed... we're now going around to our partners again with some new ideas, having done some of the techniques that I learned about. We're getting much more favorable responses from partners now. That's an example of where the stuff that we studied on the course has been directly useful. (Interview 15 Male, Board member).

Third, significant emphasis is placed on intergroup dynamics through multiple components of the curriculum. Participants widely perceived the focus on tending to intergroup and interorganisational relations as a 'seminal moment' that continued as highly relevant to managing the many boundaries within their systems. They described benefits of 'deep listening' in field projects both in order to understand the views of other actors in the system and to address resistance to change: 'it helped break some of the boundaries and barriers between the hospital and our commissioners... We managed to really improve the relationship between two sides'. They also recognised the value of focusing on groups rather than individuals in an organisation while trying to find common ground:

Rather than necessarily think of individuals within the organization, I now think about the groups. For 
example, there is a group of GPs in the organization, and there's a managerial group within the organization...not trying to make my GPs like managers and not trying to make the managers like GPs, but understanding that they are distinct groups... and they are coming from a particular standpoint, but then trying to then understand what those standpoints are in the middle. (Interview 11 Male, Clinician, Board Member).

\section{Participants describe a level of learning that sustained and amplified over time with increased complexity in work}

Participants (primarily from the 2013 and 2015 cohorts) reflected that programme learnings 'stuck' with them ('...'let people have their groups' is something that possibly every day in my working career since then has stuck with me'), although some shared learnings 'had worn off a bit'. Some explicitly characterised this retention as unusual following courses of this type:

There are things on this course that will stay with me, absolutely, and that's actually quite rare. I've been on a number of different courses, and I couldn't tell you what the benefit of those things are, but there are things on this that have stuck with me. There's only a handful of those things throughout my career that have done that for me. (Interview 18 Male, Board Member).

Several described strategies they use to retain learnings and maintain momentum beyond programme completion, ranging from keeping notes and PowerPoints to visual reminders in their workspaces ('Think Yale') and regular interactions with colleagues:

I've still got the PowerPoints. With changing jobs, I've kept them, and they come with me. I use them regularly, whether I use them explicitly and say, 'Well, I've got this off of Yale' or I use them in terms of having that conversation about, 'Well, have you thought of approaching it like this?' Do you understand what the problem is? Where's your data to justify what the problem is? (Interview 4 Male, Board Member).

As participants grow distant from the programme and typically assume increasingly complex and more senior leadership roles over time, many reflected that the learnings do not become less relevant and in fact may 'strengthen' or 'amplify as time goes on', with some learnings growing 'more relevant than (they were) at the time'. Of note, one participant described the changes as 'incremental and not as readily perceivable and for another, the relevancy of concepts was not immediately apparent as they wondered 'how valuable any of it had been'. In general, however, participants reported that they find themselves returning to concepts they learnt and implementing them in their daily work, reflecting that the tools have become 'ingrained' and a natural way of thinking and working, with one participant describing it as 'embedded in the way they behave'.

(The programme) is not absolutely forefront in our mind all the time, but that for me is probably a good sign because actually it's embedding and becoming more of a natural thing to think in that way when I'm dealing with problems... (to use) the things we've learned about cross-organizational psychology and dynamics makes me feel like I have absorbed it...it is a constitutional change in myself in how I'm managing things. (Interview 9 Female, Clinician, Senior Manager).

One specific example of a change in perspective was offered by this participant, who shared that her appreciation of the value of diverse teams had grown over time:

If you've got a team that's all the same, then you need to do something about that team, because there's whole areas that they're not covering. With things like that, my perspective on it has grown. (Interview 14, Female, Senior Manager).

While another reflected the utility of his experience and learnings from the programme in addressing the adaptive challenges within the NHS, particularly as his role becomes increasingly senior:

I'm becoming one of the more senior people in my organizations...there is a lot of respect for what I say on the board because I brought the experience and the learning which we had from Yale. As time goes by, the challenge which is facing the NHS is developing and increasing every day. What we are trying to do to address that (challenge) has to evolve. Using the programme thinking... has been very helpful. (Interview 19 Male, Clinician, Senior Manager).

\section{DISCUSSION}

Despite extraordinary investments in leadership development, the degree to which offerings are relevant to meet increasingly complex challenges is unknown. We conducted an in-depth exploration of experiences of participants in a leadership development programme in order to understand which elements of the programme are most relevant to working in complex systems, and whether learnings in fact 'stick' and perhaps change over time. Participant experiences were quite consistent across cohort, gender and professional background. Our study offers a deeper understanding of specific aspects of leadership development programmes that are relevant in dynamic, highly complex, cross-sectoral settings. Although high-level strategy and systems level thinking may not appear to be applicable for those in more circumscribed leadership roles, many of the core concepts are broadly applicable, such as psychological safety and intergroup dynamics. 
Our findings are consistent with prior studies that found development of a shared understanding of strategic concepts is an outcome valued by participants. ${ }^{19}$ The best leadership development programmes produce enduring changes in employee behaviour; ${ }^{39} 40$ participants reported leadership approaches and behaviours that not only sustained but in fact amplified over time. Of note, although participants consistently described the value of the 'Yale methodology' (their term), we do not believe it to be a proprietary model. Their descriptions highlighted learnings related to development of shared understanding of the problem through stakeholder engagement and root cause analysis process that incorporates multiple methods and perspectives. We hypothesise that many other stepwise approaches to systematically understanding and addressing complex problems, if implemented in an effective way, would support similar breakthroughs.

Leadership development (as compared with leader development) requires cultivating capacity to address the relational aspects of work, and to work collaborative in diverse teams. ${ }^{240-42}$ Our findings cohere with and extend this literature, as participants both appraised these programmatic elements as among the most valuable and provided rich detail about these new ways of working. Furthermore, although problem-focused field projects are promoted as a useful method for leadership development, ${ }^{43}$ few programmes integrate extensive field work supported by coaching as a central component of the curriculum ${ }^{15}$ and little is known about how participants experience field projects, or whether learnings sustain over time. ${ }^{42}$ This study contributes new insights, as participants described how competencies gained through the field projects were broadly applicable and extended beyond the project itself. ${ }^{44} 45$

Several limitations must be noted. First, social desirability response bias ${ }^{46}$ may have occurred. However, we used established techniques ${ }^{32} 33$ to encourage participants to share both positive and negative experiences. ${ }^{25}$ In addition, the randomisation of the complete sample list and low refusal rate reduced the likelihood that we did not select only those who had a positive view of the programme. Although the refusal rate was low, it is possible that those who refused or missed the interview had a more negative or neutral experience with the programme. Second, while there are benefits of having the evaluation team familiar with the programme in terms of the quality and rigour of data collection and analysis (see, eg Guba's Evaluator as Instrument), ${ }^{28}$ we recognise the potential risk to objectivity. Therefore, to ensure transparency, we report all negative experience and comments in online supplementary table 3 . Third, a large proportion of participants came from one geographic region; the programme was initially delivered only in that region, and only began recruiting at the national level in 2016. Nevertheless, the sample includes geographic spread as feasible. We are unaware of any systematic biases that might arise from this regional concentration, and responses from that region were not discernably different from themes that emerged across all participants. Finally, we explored the value of specific aspects of a leadership programme as perceived by alumni, as opposed to the quantitative impact on systems performance driven by participants' field experiences. While we compile extensive data on the field projects, the projects are varied in their objectives and evaluation plans, hence it would not be meaningful to 'roll up' summary impact on organisational or system-wide performance. Further, as described in the participant narratives, alumni go on to effect change in organisational capacity and system performance well beyond their initial field projects.

Despite global recognition of the importance of cultivating leadership to drive achievement of health systems goals, and a proliferation of leadership development programmes using myriad approaches, empirical work to understand the most valuable components has been lacking. This work highlights specific programme design features that may help promote relevance and impact, shows how programme learnings can be translated into practice in meaningful ways and describes potential for the benefits of successful leadership development efforts to amplify, not fade, over time. We hypothesise learnings 'stuck' and grew over time for several reasons: the intentional creation of a diverse learning community, the integration of leading-edge scholarship into a practical 9-month field project to embed new habits, the curricular balancing of tools and approaches for both strategic thinking and intergroup management ${ }^{41}$ and the resident-style experiences. Future research could explore these hypotheses, as well as the potential value of online communities (such as WhatsApp) in supporting alumnae to retain and apply learnings over time. Nevertheless, findings may be useful to those commissioning leadership development efforts, those designing and delivering them and those seeking to enrol for their own professional growth.

\section{Twitter Leslie A Curry @lesliecyale}

Acknowledgements We would like to acknowledge Professor Patrick Geoghegan, OBE; Peter Wadum-Buhl, MBA, Dip COT, DMS; Elizabeth Bradley, PhD and David Berg, $\mathrm{PhD}$ for their extraorindarily important contributions to this work.

Contributors LC and EL conceived of and led the study; AA and NHA conducted data collection; EL, EC, AA, NHA and EL participated in qualitative data analysis and synthesis; all authors made substantive contributions to the manuscript and reviewed and approved the final submission. All authors had full access to all of the data in the study and can take responsibility for the integrity of the data and the accuracy of the data analysis.

Funding The authors have not declared a specific grant for this research from any funding agency in the public, commercial or not-for-profit sectors.

Competing interests None declared.

Patient consent for publication Not required.

Ethics approval The Human Investigation Committee at the Yale University School of Medicine approved the research protocol.

Provenance and peer review Not commissioned; externally peer reviewed.

Data availability statement Data are available upon reasonable request. All relevant data are within the paper and its supporting information files. These 
detailed qualitative data are maintained in an Atlas.ti database. We are concerned given the specificity of the study setting, size of sample, and nature of the phenomenon studied, that it is not possible to fully de-identify data. We are willing to consider any reasonable request, provided anonymity of participants can be preserved.

Open access This is an open access article distributed in accordance with the Creative Commons Attribution Non Commercial (CC BY-NC 4.0) license, which permits others to distribute, remix, adapt, build upon this work non-commercially, and license their derivative works on different terms, provided the original work is properly cited, appropriate credit is given, any changes made indicated, and the use is non-commercial. See: http://creativecommons.org/licenses/by-nc/4.0/.

\section{ORCID iD}

Leslie A Curry http://orcid.org/0000-0002-3419-4654

\section{REFERENCES}

1 Bradley EH, Nembhard I, Taylor L, et al. Leadersip and management: a frramework for action. In: Burns L, Weiner B, eds. Shortell and Kaluzny's health care management: organization design and behavior. New York: Delmar Cengage Learning, 2019: 32-55.

2 McAlearney AS. Using leadership development programs to improve quality and efficiency in healthcare. $J$ Healthc Manag 2008;53:319-31.

3 Nembhard IM, Edmondson AC. Making it safe: the effects of leader inclusiveness and professional status on psychological safety and improvement efforts in health care teams. J Organ Behav 2006;27:941-66.

4 Baggs JG, Schmitt MH, Mushlin Al, et al. Association between nursephysician collaboration and patient outcomes in three intensive care units. Crit Care Med 1999;27:1991-8.

5 Bohmer RMJ. Leading clinicians and clinicians leading. N Engl J Med 2013;368:1468-70

6 Clemmer TP, Spuhler VJ, Oniki TA, et al. Results of a collaborative quality improvement program on outcomes and costs in a tertiary critical care unit. Crit Care Med 1999;27:1768-74.

7 Curry LA, Brault MA, Linnander EL, et al. Influencing organisational culture to improve Hospital performance in care of patients with acute myocardial infarction: a mixed-methods intervention study. BMJ Qual Saf 2018;27:207-17.

$8 \mathrm{Kim}$ MM, Barnato AE, Angus DC, et al. The effect of multidisciplinary care teams on intensive care unit mortality. Arch Intern Med 2010;170:369-76

9 Neily J, Mills PD, Young-Xu Y, et al. Association between implementation of a medical team training program and surgical mortality. JAMA 2010;304:1693-700.

10 McAlearney AS. Executive leadership development in U.S. health systems. J Healthc Manag 2010;55:206-24.

11 National Center for Healthcare Leadership. Physician leadership development programs: best practices in healthcare organizations, 2014. Available: http://www.nchl.org/Documents/Ctrl_Hyperlink/ NCHL_Physician_Leadership_Development_White_Paper_Final 05.14 uid9142015803251.pdf [Accessed 4 Oct 2019].

12 Storey J. What next for Strategic-level leadership research? Leadership 2005;1:89-104.

13 Bradley EH, Brewster AL, McNatt Z, et al. How guiding coalitions promote positive culture change in hospitals: a longitudinal mixed methods interventional study. BMJ Qual Saf 2018;27:218-25.

14 Heifetz RA, Laurie DL. The work of leadership. Harv Bus Rev 2001;79:131-41.

15 Frich JC, Brewster AL, Cherlin EJ, et al. Leadership development programs for physicians: a systematic review. J Gen Intern Med 2015;30:656-74.

16 Blackler F, Kennedy A. The design and evaluation of a leadership programme for experienced chief executives from the public sector. Manag Learn 2004;35:181-203.

17 Gosling J, Mintzberg H. Management education as if both matter Manag Learn 2006;37:419-28.

18 Pedler M. Action learning for managers. Aldershot: England Gower Pub, 2008.

19 Watkins KE, Lysø IH, deMarrais K. Evaluating executive leadership programs: a theory of change approach. Adv Dev Hum Resour 2011;13:208-39.

20 Revans RW. Action learning: new techniques for management. London: Blond and Briggs, LTD, 1980.

21 Green PL, Plsek PE. Coaching and leadership for the diffusion of innovation in health care: a different type of multi-organization improvement collaborative. Jt Comm J Qual Improv 2002;28:55-71.
22 Korschun HW, Redding D, Teal GL, et al. Realizing the vision of leadership development in an academic health center: the Woodruff leadership Academy. Acad Med 2007;82:264-71.

23 Anderson MM, Garman AN. Leadership development in healthcare systems: toward an evidence-based approach, 2014. Available: http://nchl.org/Documents/Ctrl_Hyperlink/NCHL_Leadership_ Survey White_Paper_Final_05.14_uid6232014300422.pdf [Accessed 4 Oct 2019].

24 Careau E, Biba G, Brander R, et al. Health leadership education programs, best practices, and impact on learners' knowledge, skills, attitudes, and behaviors and system change: a literature review. J Healthc Leadersh 2014;6:39-50.

25 Patton MQ. Qualitative research \& evaluation methods. 3 ed. Thousand Oaks, Calif: Sage Publications, 2002.

26 Pope C, van Royen P, Baker R. Qualitative methods in research on healthcare quality. Qual Saf Health Care 2002;11:148-52.

27 Morse JM. The significance of saturation. Qual Health Res 1995;5:147-9.

28 Guba EG, Lincoln YS. The evaluator as instrument. In: Guba EG, Ys L, eds. EffectiveEvaluation. San Francisco: Jossey-Bass, 1981.

29 Hammersley M, Atkinson P. Ethnography: principles in practice. New York: Tavistock, 1983.

30 Kvale S. Interviews An Introduction to Qualitative Research Interviewing. Thousand Oaks, CA: Sage Publications, 1996.

31 McCracken G. The long interview. Newbury Parks: Sage Publications, 1988.

32 Creswell JW, Miller DL. Determining validity in qualitative inquiry. Theory Pract 2000;39:124-30.

33 Denzin NK. Interpretive interactionism. Newbury Park, CA: Sage, 1989.

34 Bradley EH, Curry LA, Devers KJ. Qualitative data analysis for health services research: developing taxonomy, themes, and theory. Health Serv Res 2007;42:1758-72.

35 Glaser BG, Strauss AL. The discovery of grounded theory; strategies for qualitative research. Chicago: Aldine Pub. Co., 1967.

36 Miles MB, Huberman AM. Qualitative data analysis : an expanded sourcebook. 2nd ed. Thousand Oaks: Sage Publications, 1994.

37 Curry LA, Nembhard IM, Bradley EH. Qualitative and mixed methods provide unique contributions to outcomes research. Circulation 2009;119:1442-52.

38 Taylor LA, Tan AX, Coyle CE, et al. Leveraging the social determinants of health: what works? PLoS One 2016;11:e0160217.

39 Kirkpatrick DL, Kirkpatrick JD. Transferring learning to behavior : using the four levels to improve performance. 1st ed. San Francisco, Calif: Berrett-Koehler Publishers, 2005.

40 Dannels SA, Yamagata H, McDade SA, et al. Evaluating a leadership program: a comparative, longitudinal study to assess the impact of the executive leadership in academic medicine (ELAM) program for women. Acad Med 2008;83:488-95.

41 Berg DN. Intergroup relations: an abbreviated update. Journal of Management Education 1979;3:48-51.

42 Day DV. Leadership development: a review in context. Leadersh $Q$ 2000;11:581-613.

43 Blumenthal DM, Bernard K, Bohnen J, et al. Addressing the leadership gap in medicine: residents' need for systematic leadership development training. Acad Med 2012;87:513-22.

44 McAlearney AS. Leadership development in healthcare: a qualitative study. J Organ Behav 2006;27:967-82.

45 Snook S, Nohria N, Khurana R. The handbook for teaching leadership: knowing, doing, and being. London: Sage, 2010.

46 Sudman S, Bradburn NM, Schwarz N. Thinking about answers : the application of cognitive processes to survey methodology. First edition. ed.

47 Carlile PR. Translating, and transforming: an integrative framework for managing knowledge across boundaries. Organ Sci 2004; $15: 555-68$

48 Santos FM, Eisenhardt KM. Organizational boundaries and theories of organization. Organization Science 2005;16:491-508.

49 Jaques E. In praise of hierarchy. Harv Bus Rev 1990;68:127-33.

50 Ronay R, Greenaway K, Anicich EM, et al. The path to glory is paved with hierarchy: when hierarchical differentiation increases group effectiveness. Psychol Sci 2012;23:669-77.

51 Berg DN. Resurrecting the muse: followership in organizations. In: Klein EB, Gabelnick F, Herr P, eds. The psychodynamics of leadership. Madison, CT: Psychosocial Press, 1990: 27-52.

52 Alderfer CP. An intergroup perspective on group dynamics. In: Lorsch J, ed. Handbook of organizational behavior. Englewood Cliffs, NJ: Prentice Hall, 1987: 190-222.

53 Berg DN. Senior executive teams: not what you think. Consult Psychol J: Pract and Res, 2005. 
54 Curry LA, O'Cathain A, Clark VLP, et al. The role of group dynamics in mixed methods health sciences research teams. J Mix Methods Res 2012;6:5-20.

55 Alderfer CP. The practice of organizational diagnosis. New York: Oxford University Press, 2011.

56 Berg DN. Levels of analysis: diagnosis \& intervention. Available: http://csms.org/wp-content/uploads/2015/04/Levels-OrganizationalAnalysis.pdf [Accessed 7 Dec 2016].

57 Curry LA, Krumholz HM, O'Cathain A, et al. Mixed methods in biomedical and health services research. Circ Cardiovasc Qual Outcomes 2013;6:119-23.
58 PSYTECH International. Fifteen factor questionnaire plus. Available: https://www.psytech.com/Assessments/FifteenFactorQuestionnai rePlus [Accessed 6 Feb 2020].

59 Watson G, Glaser EM. Watson-Glaser Critical Thinking Appraisal. Yonkers, New York: World Book Company, 1952.

60 The Myers-Briggs Company. Myers-Briggs type Indicator®. Available: https://www.cpp.com/products/mbti/index.aspx [Accessed 6 Feb 2020].

61 Lazarus RS, Folkman S. Stress, appraisal and coping. New York: Springer, 1984.

62 Kotter JP. What leaders really do. Harv Bus Rev 2001;79:85. 